\title{
Autoimmunity in the Abdominal Aortic Aneurysm and its Association with Smoking
}

\author{
M. David Tilson, MD* \\ Department of Surgery, College of Physicians and Surgeons, Columbia University, New York, New York, USA
}

\begin{abstract}
Smoking increases the risk of abdominal aortic aneurysm (AAA) in both humans and mice, although the underlying mechanisms are not completely understood. An adventitial aortic antigen, AAAP-40, has been partially sequenced. It has motifs with similarities to all three fibrinogen chains and appears to be connected in evolution to a large family of proteins called fibrinogen-related proteins. Fibrinogen may undergo non-enzymatic nitration, which may result from exposure to nitric oxide in cigarette smoke. Nitration of proteins renders them more immunogenic. It has recently been reported that anti-fibrinogen antibody promotes AAA development in mice. Also, anti-fibrinogen antibodies are present in patients with AAA. These matters are reviewed in the overall context of autoimmunity in AAA. The evidence suggests that smoking amplifies an auto-immune reaction that is critical to the pathogenesis of AAA.

Copyright @ 2017 Science International Corp.
\end{abstract}

\section{Key Words:}

Abdominal aortic aneurysm • Smoking • Autoimmunity • Nitric oxide • Fibrinogen

\section{Introduction}

Compared with the relatively small effects of genetic mutations or polymorphisms on the risk for abdominal aortic aneurysm (AAA), smoking presents a much greater risk by as much as an order of magnitude. For example, the risk-odds ratio of a well-established polymorphism associated with AAA, DAB2IP

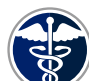

Fax +1 2037853552

E-Mail: aorta@scienceinternational.org

http://aorta.scienceinternational.org

\author{
(c) 2017 AORTA \\ Published by Science International Corp. \\ ISSN 2325-4637 \\ Accessible online at: \\ http://aorta.scienceinternational.org
}

on chromosome 9q33.2, is 1.2 [1], and the risk-odds ratio for another polymorphism on $9 \mathrm{p} 21$ is 1.3 [2]. By contrast, the risk-odds ratio for heavy smoking is 12.0 [3], comparable only to the risks of age and male sex. Smoking also promotes aneurysm formation in laboratory mice $[4,5]$. A molecular explanation for the effect of smoking has been proposed [6]. The purpose of this communication is to explain the hypothesis that nitric oxide (NO) in tobacco smoke nitrates a protein related to the fibrinogen superfamily in the aortic adventitia and thus enhances its antigenicity. In particular, I discuss four factors that are often associated with diseases of autoimmunity $[7,8]$ : genetic susceptibility, inflammation, matrix metalloproteinases (MMPs), and antibodies and autoantigens.

\section{Human Genetics of AAA}

Clifton reported three brothers affected with AAA in 1977 [9]. In 1978, the author operated on a friend and colleague to repair an AAA and bilateral popliteal artery aneurysms on separate occasions. The patient was otherwise healthy, fit, normotensive, and normocholesterolemic. His angiographic studies were unremarkable except for his aneurysms. There was no detectable atherosclerosis. His mother had died of a ruptured AAA, raising the question of whether a genetic predisposition was at work. In 1980, we reported on numerous differences between groups of patients undergoing aortic surgery for AAA versus occlusive (OCC) disease [10]. These differences (age, sex,

\footnotetext{
* Corresponding Author:

M. David Tilson, MD

Department of Surgery

College of Physicians and Surgeons, Columbia University

105 Garth Road, Apt B2, Scarsdale, New York 10583, USA

Tel.: +1 914725 7146; E-Mail: mdt1@columbia.edu
} 
and other features) provided a basis for questioning the notion that atherosclerosis causes AAA. These anecdotes are just a few factors that drew me into a career-long interest in the human genetics of AAA and the pathobiology of the disease.

Our first effort at clinical genetics in 1984 was a small study of patterns of inheritance in 14 families with a total of 41 affected members [11]. The conclusion from this analysis was that there might be X-linked and autosomal dominant forms of the disease. Extending this study to include a total of 50 families, we concluded that if there was only a single locus explaining the inheritance of AAA disease, it was likely to be autosomal dominant [12].

Many confirmations of the hypothesis of a genetic association followed. The first study with a proper control group was performed by Johansen and Koepsell [13], who reported on the family histories of 250 AAA patients and 250 control patients. Whereas $19.2 \%$ of AAA patients reported an affected first-order relative, only $2.4 \%$ of control patients were aware of an affected relative. The possibility that being born into a smoking family might have a "paragenetic" effect was not considered in the early studies. I use the neologism "paragenetic" to suggest that a phenotype may run in families without a genetic basis. For example, if both parents are non-smokers and disapprove of smoking, it seems less likely that their children will take up the habit.

Initial efforts to root the genetic hypothesis in a molecular basis involved the candidate gene approach [14]. Our first contribution implicated the TIMP-1 gene [15], which was subsequently confirmed by a larger study [16]. Another interesting candidate was the major histocompatibility complex molecular locus DR-15 (originally protein DR-2) [17, 18]. Other investigators also showed interest in the major histocompatibility complex [19]. In addition, we found an identical amino acid substitution in the ferritin light chain gene in 2 of 19 AAA patients [14].

Collagen XI-alpha 1 was of special interest to our laboratory for multiple reasons. It was overexpressed 38-fold in a AAA-derived fibroblast cell line (a clear outlier) relative to a cell line from normal aortic fibroblasts. It was subject to alternative slicing, with cartilage- and aorta-specific variants in exon 6. Furthermore, it was selectively expressed in the adventitia of the normal aorta. Sequencing of exon 6 revealed a heterozygous $\mathrm{G}>\mathrm{T}$ signal 70 bp upstream from exon 6 in 14 of 19 consecutive AAA samples [14].

A plethora of additional genes were proposed by others, and the situation became more complicated. In 2007, Sandford et al. summarized a decade of effort [20], concluding that "while the candidate gene approach has led to significant advances in understanding the pathogenesis of $A A A$, it is unlikely that a single gene polymorphism will hold the key to aneurysm formation. Whole gene studies are likely to be required...." These studies are now referred to as genome wide association studies (GWAS).

An advantage of GWAS is that no knowledge of AAA pathobiology is required, as it is a brute force approach. A disadvantage is that it is inherently large-scale and resource-intensive. A recent meta-analysis of six GWAS datasets with a total of 10,204 AAA patients and 107,766 control patients had 116 multinational co-authors [21]. Four novel single nucleotide polymorphisms (SNPs) were identified and added to a list of five others identified from previous studies. The pathobiological roles of all nine SNPs in AAA disease remain unknown. The summary situation is mostly unchanged since the review by Saratzis et al. in 2015 [22], which concludes that AAA represents a "multifactorial disease, with the likelihood that there are multiple variants of very low effect contributing to the overall genetic disease risk." Thus, the genetic approaches that seemed so promising 25 years ago have failed to uncover a "smoking gun."

This discussion would be incomplete without mentioning that we are now entering a "post-GWAS" era [23]. Another problem with GWAS is that the variations detected so far occur in non-coding DNA sequences, so their significance is not obvious. An alternative has been adoption of the epigenetic approach. Epigenetics refers to stable differences in gene expression that are "not attributable to DNA sequence variation" [24]. Joehanes et al. [25] report that the "epigenetic signatures of cigarette smoking" reflect "a broad impact on genome-wide methylation." In addition to methylation, the study of microRNAs is another example of an epigenetic modification. No doubt there will be interesting developments in these areas in the future. 


\section{The Role of Inflammation}

In 1986, Beckman proposed that autoimmunity plays a role in the pathogenesis of AAA [26]. Beckman observed an infiltration of plasma cells in 31 of 156 AAA specimens from patients who were not thought on clinical grounds to be examples of the "inflammatory variant" of aneurysms. He speculated that there was an immune reaction against atherosclerotic elements in the AAA wall, consistent with the view at that time that atherosclerosis causes non-specific aneurysms (the term "non-specific" is used because the Joint Committee on Reporting Standards, sponsored by the Society of Vascular Surgery and International Society for Cardiovascular Surgery, recommended in 1991 that this terminology replace the conventional usage "atherosclerotic aneurysm" due to insufficient evidence that atherosclerosis actually caused the disease [27]).

Another example of a Th2 (allergic or autoimmune) response appeared in 1990 [28], when I was invited to write a book chapter on the pathology of AAA. The assistance of a pathologist at Yale University School of Medicine was enlisted (G. J. W. Smith), and a "séance" was arranged to compare a tray of AAA slides with a tray of atherosclerotic aortic slides. One of the most conspicuous findings was the virtual absence of iron-hematoxylin-reactive elastin in the media of AAA specimens. Another finding was that there was inflammatory infiltrate in AAA at the junction of the outer media with the adventitia. In some cases, this infiltrate was so impressive that our pathologist remarked that it was reminiscent of that seen when syphilis was common. The infiltrate was primarily plasmacytic, and there were Russell bodies within areas of inflammation.

Russell bodies are eosinophilic aggregates of immunoglobulin $\mathrm{G}(\mathrm{lg} G)$ seen in plasma cells undergoing excessive synthesis of antibodies in autoimmune conditions. They reflect an overstuffed endoplasmic reticulum. The role of inflammation in the etiology of AAA was further elaborated by Brophy et al. in 1991 [29]. A conspicuous mononuclear infiltrate was present in 8 of 10 specimens, primarily located at the adventitial/medial junction. The presence of Russell bodies was confirmed. In addition, large quantities of immunoglobulins were extractable from AAA tissue by affinity to protein $A$.
Evidence for a Th-1 (cytotoxic) response appeared in 1990, when Koch et al. formally proposed that "immunophenotypic analysis suggested an immune-mediated response" in non-specific AAA [30]. The analysis was based on 32 specimens: 4 normal aortas (NLs), 6 OCC aortas, 17 AAAs, and 5 inflammatory AAAs (IAA). Monoclonal antibodies were used to identify the various cell types. The extent of inflammatory infiltrate was IAA > AAA > OCC > NL. The authors interpreted these findings as a spectrum, suggesting that a single disease progressed from OCC to AAA. I advanced the notion that AAA and OCC are two separate disease processes with common risk factors like smoking and hypertension. The aneurysm might actually initiate atherosclerotic degeneration of the subendothelium $[31,32]$. A study in mice suggests that aortic dissections precede the onset of atherosclerosis [33]. Other investigators have suggested that the two processes may be "running in parallel" [34].

More recent studies have significantly expanded the evidence for a Th- 1 response in AAA [35, 36]. Amplification of beta-chain T-cell receptor transcripts from AAA lesions suggests that 9 of 10 patients have substantial proportions of identical polymerase chain reaction products. The authors conclude that "AAA is a specific antigen-driven T-cell disease."

\section{Matrix Metalloproteinases}

MMP activation or deregulation is a typical feature of autoimmune diseases. Loss of elastin is a sentinel histochemical feature of AAA, and Reilly et al. were the first to report that the "killer elastase" is a metalloproteinase with a molecular weight of $\sim 80 \mathrm{kDa}$ [37]. We subsequently identified it as gelatinase $B$ or MMP-9 [38]. Mammalian collagenase (MMP-1) [39] and stromelysin (MMP-3) [40] are also present. Immunohistochemically, MMP-9 is co-distributed with macrophages, whereas MMP-1 is associated with endothelial cells of neovascularizing vessels and mesenchymal-like cells in the infiltrate [41]. MMP-2 is expressed by a fibroblast cell line cultured from a human AAA explant but not by a normal aortic cell line. The MMP-2 cell line is stable in its expression of MMP2 over multiple passages (unpublished observations). Cytokines that regulate these MMPs are also elevated in AAA [42]. 
These observations are interesting, but they are phenomenological and do not establish causal relationships. The development of gene knockout (KO) technology in inbred mice has led to a new era in AAA experimentation. For example, Pyo et al. [43] report that AAA does not develop in MMP-9 null/null mice in the elastase-perfusion model. The AAA-susceptible phenotype is "rescued" by bone marrow transplantation (macrophages) from wild-type mice. These studies show that MMP-9 is a necessary condition for AAA. A similar strategy was employed by Longo et al. [44] in the abluminal (peri-adventitial) calcium chloride model. No aneurysms occurred in MMP-9 or MMP$2 \mathrm{KO}$ mice, suggesting that both macrophage- and mesenchymal-derived MMPs are required and may work in concert to produce AAA.

It is possible that the nicotine in burning tobacco (and not some other component of the smoke) initiates or promotes the smoking/AAA association. Nicotine exposure equivalent to plasma levels in smokers augments MMP-9 and MMP-2 expression by macrophage and vascular smooth muscle cell lines in vitro [45]. Of course, in vitro findings do not always translate smoothly to the situation in vivo. Bergoeing et al. [4] found that cigarette smoking increases aortic dilatation in vivo without affecting the expression of MMP-9 or MMP-12. Wang et al. [46] report that acute infusions of nicotine produce aneurysms in Apo-E-deficient mice, but the aneurysms that occur in this model resemble those induced by angiotensin (Ang) II. In our experience, these AAAs begin as aortic dissections and not as a typical fusiform AAAs. Guo et al. [47] report that the JNK inhibitor, SP600125, attenuates the nicotine plus Ang II model of AAA formation, but again, these AAAs are false aneurysms.

Maegdefessel et al. [48] report that nicotine pellets (versus placebo) augment aneurysmal expansion in the elastase-perfusion model. This model avoids some of the difficulties of the Ang II model. It also avoids the problem of "smoker's hypertension" that develops in chronically smoke-exposed mice [49], which may independently promote AAA formation. Blood pressure measurements at 14 days showed no difference between nicotine and placebo groups, but more extensive observations might be useful to rule out this potentially misleading possibility. Of course, a direct effect of nicotine in pellets and enhancement of autoimmunity by smoke are not mutually exclusive as valid explanations of the smoking/AAA association.

\section{Antibodies and Autoantigens}

Capella et al. [50] carried out experiments to determine whether increases in IgG in AAA tissue are subclass-specific (by enzyme-linked immunosorbent assay (ELISA) with monoclonal antibodies) and whether the $\lg G$ complex is associated with increases in complement C3. Seven AAA, four OCC, and two NL aortic specimens were evaluated. Comparing by subclass, IgGs were elevated in AAA over NL by $193 \times$ for $\lg \mathrm{l} 1,160 \times$ for $\lg \mathrm{g} 2,389 \times$ for $\lg G 3$, and $627 \times$ for $\lg G 4$. Increases in IgGs in AAA specimens over NL and OCC specimens by subtype were statistically significant $(p<0.01)$. ELISA showed a $125 \times$ increase in immunoreactive $C 3$ in soluble extracts of $A A A$, and Western immunoblots revealed multiple $\mathrm{C} 3$ immunoreactive isoforms or degradation products.

With evidence that immunoglobulins are recoverable from AAA tissue, interest intensified to find the aortic autoantigen(s). Gregory et al. [51] purified lg from serial AAA specimens and found that it was immunoreactive with a protein of $\sim 80 \mathrm{kDa}$ in Western blots of 11 of 14 (79\%) AAA patients versus 1 of 9 (11\%) control patients ( $p=0.002$, Fisher's exact test). By immunohistochemistry, antibodies extracted from AAA specimens were immunoreactive with a microfibrillar protein in the matrix of the adventitia of the normal aorta.

This experiment was repeated by Chew et al. [52], who confirmed that AAA immunoglobulins are immunoreactive with a matrix protein of $\sim 80 \mathrm{kDa}$, extractable from aneurysmal aortas by high concentrations of guanidinium hydrochloride. We inferred that this was a dimeric form of an AAA antigenic protein with a molecular weight of $\sim 40 \mathrm{kDa}$, which had been affinity-purified with antibodies from AAA specimens [53]. This protein was named AAAP-40 for aneurysm-associated antigenic protein $40 \mathrm{kDa}$.

The partial amino acid sequence of AAAP-40 was determined. It had homology to a protein in pig with an aorta-specific tissue distribution. The porcine protein had been discovered and named microfibril-associated glycoprotein $36 \mathrm{KDa}$ by Kobayashi et al. [54]. AAAP-40 has seven tyrosine residues, including one 
tyrosine doublet, which are prime sites for nitration [55]. AAAP-40 also has short homologies with all three chains of fibrinogen, suggesting that its evolutionary history placed it close to the common ancestor of the three modern chains. We calculated the evolutionary distance of AAAP-40 from fibrinogen-beta (measured in point-accepted mutation rates [PAMs]; among fibrinogen-related proteins [FRePs], a PAM unit is about a million years). Only 30 PAMs separated AAAP-40 from fibrinogen-beta [56]. These results agreed with a neighbor-joining tree computing the relatedness of MAGP-36, AAAP-40, MFAP-4, and a "fibrinogen-like protein of the sea cucumber" [57].

Antibody against a unique amino acid sequence of AAAP-40 (not found in any other mammalian protein) was immunoreactive with adventitial microfibril of the human aorta and selected other vessels $[58,59]$. This antibody was also immunoreactive with a microfibrillar protein in mouse aortic adventitia [60]. Figure 1 illustrates that a commercial antibody against fibrinogen-beta is immunoreactive with a microfibrillar protein in the human aortic adventitia. Figure 2 shows

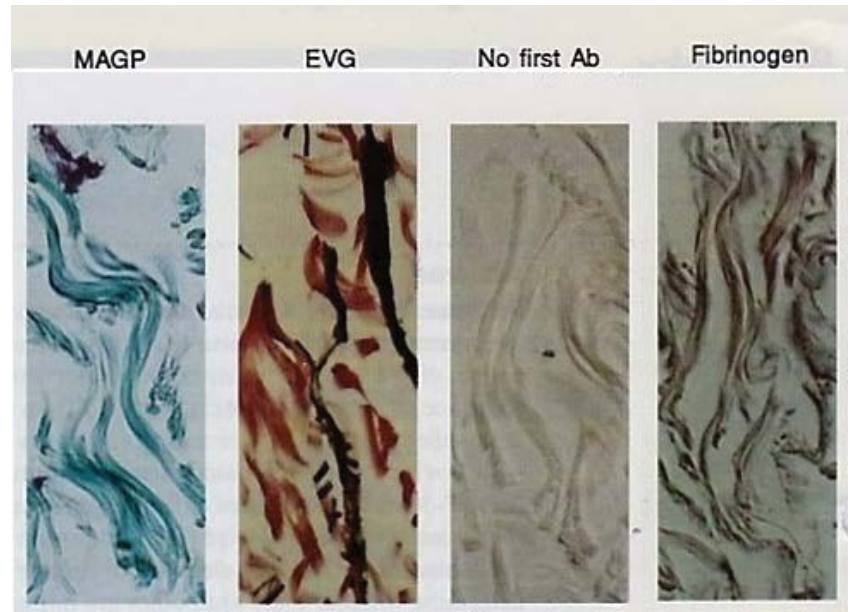

Figure 1. Tissue sections from the adventitia of a normal human (cadaver donor) aorta photographed at 400x. An immunohistochemical stain (Gomori's aldehyde fuchsin) was used for microfibril-associated glycoprotein (MAGP). Verhoeffıs elastic stain (EVG) was used for collagen (pink) and elastin (black). Immunohistochemistry employed rabbit anti-human fibrinogen as a primary antibody and goat anti-rabbit Ig as a secondary antibody. No primary antibody was used as a control. MAGP and fibrinogen co-distributed with collagen (pink) in EVG staining. The elastin of the adventitia did not have the lamellar organization characteristic of the arterial media. that AAAP-40 is site-specifically expressed in the human arterial tree. It is abundant in the aorta, common iliac, internal iliac, and popliteal arteries but is barely detectable in the external iliac artery. This distribution corresponds to the susceptibility of the different vessels to aneurysm formation [10,61]. Taken together, these observations suggest that the AAA autoantigen is a normal constituent of the aortic adventitia and not a product of atheromatous degeneration.

\section{Smoking Promotes AAA in Mouse Models}

Stolle et al. [5] report that cigarette smoke promotes AAA in an Ang II/Apo-E-deficient mouse model. Although it is notable that smoke exerts effects in this model, we found that APO-E deficiency is not required for AAA formation. We had success in inducing AAA in normal C57/Bl6 mice that were selected only for advanced age (i.e., retired breeders) $[62,63]$.

Bergoeing et al. [4] adapted the elastase perfusion mouse model to determine whether tobacco smoke lowers the threshold of aortic injury required for AAA development. The adaptation involved changing the concentration of elastase in the perfusate, resulting in high-dose, standard-dose, and low-dose regimens. Exposure to tobacco smoke began 2 weeks before perfusion and continued until sacrifice 2 weeks after

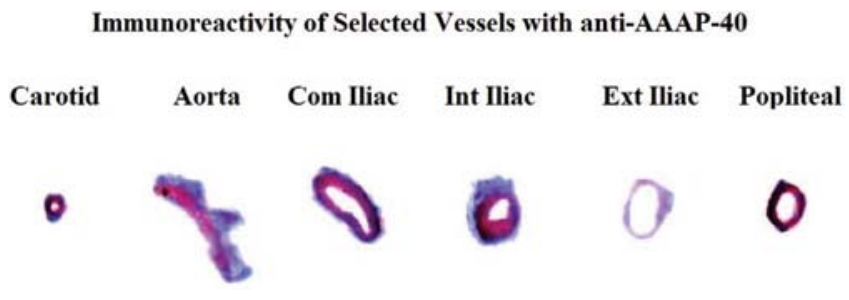

Figure 2. Immunohistochemical studies of human arterial segments from the autopsy of a patient with no abdominal aortic aneurysm (AAA) and minimal occlusive disease. The antibody was rabbit anti-human AAAP-40, raised against a synthetic peptide, based on a unique sequence not found in any other mammalian protein (-GMAKEYDGFQYT). Staining was performed in one batch for all sections. Immunoreactive protein stained blue in the adventitia of the aorta and the aneurysm-prone popliteal, internal, and common iliac arteries. The aneurysm-resistant external iliac artery exhibited minimal staining. We were surprised to note staining of the carotid artery, but this finding may explain the elongation often seen in AAA patients. 
perfusion. Smoking resulted in larger aneurysms in low-dose mice (aortic diameter increased by 134\%) compared with non-smoking low-dose mice. There was no difference in MMP-9 expression between smoking and non-smoking mice.

In parallel with human AAA disease, after a mouse model has been initiated by smoke exposure, enhanced expression of the aneurysm phenotype persists even after a smoke-free interval. Jin et al. [64] found that after smoke exposure for 6 weeks followed by no smoke exposure for another 6 weeks, the promoting effect was still in force. They proposed three possible explanations for the smoking effect: 1) a persistent increase in MMP activity; 2) a persistent direct injury to the aorta; or 3) promotion of an immune response. They found that smoking overrode MMP effects, as the smoking effect persisted even in doxycycline-treated mice or those with null/null elastolytic deficiencies. Injury to the aorta was ruled out by direct electron microscopic studies. Thus, the promotion of an immune response was favored because leukocytes from smoke-exposed mice localized to the aneurysms of smoke-free mice and increased their aortic diameters. Apparently, after leukocytes are initiated, possibly by exposure to nitro-tyrosine in aortic FRePs, they acquire memory for promoting an autoimmune response.

Zhou et al. [65] identified a natural IgG antibody in mice that binds to fibrinogen and initiates the inflammatory response that culminates in AAA development. They found that a mouse anti-fibrinogen antibody enhances AAA formation. Also, they reported that $A A A$ patients have circulating antibodies against "fibrinogen or fibrinogen-associated epitopes in human aneurysmal tissue". This finding confirms the rationale for the use of ELISA to detect antibodies as a screening test for the disease as proposed by Knoetgen et al. in 1997 [66].

\section{Smoking-Induced Nitration of Plasma and Tissue Proteins}

Tyrosine nitration is a modification that may change the rate of proteolytic degradation of nitrated proteins. Protein nitration in cardiovascular diseases has been extensively reviewed by Turko and Murad [67]. The au- thors note that the process is selective (e.g., residue-, protein-, and tissue-specific). Not all tyrosine residues of a protein are nitrated, and not all proteins are targets for nitration. Typically, one or two tyrosine residues are site-specifically nitrated. The product of nitration is 3-nitro-tyrosine, which has been established as a biomarker of "nitro-oxidative stress" [68].

Nitrotyrosine in plasma proteins is increased in smokers with chronic obstructive pulmonary disease, consistent with "increased nitration associated with inflammatory processes" [69]. Nitrated plasma proteins are also increased in lung cancer patients [70]. Fibrinogen is among the plasma proteins that are nitrated.

Our interest in this subject matter arose in the context that cigarette smoke contains substantial amounts of NO [71]. We found that the nitrite content of AAA tissue is comparable to levels that were once considered possibly carcinogenic in smoked sausage [72]. This concentration of nitrite (but not nitrate) damages the aortic matrix in vitro [73] and leads to tyrosine depletion in a solution of collagen [74]. Immunogenicity of tyrosine-nitrated self- proteins has been reviewed in the context of understanding the mechanisms leading to autoantibody production [55]. Structurally modified self-proteins give rise to new epitopes to which $T$ and $B$ lymphocytes are not tolerant. These nitrated proteins elicit cellular and humoral responses in mice.

\section{The Smoking/Autoimmune Hypothesis}

AAA has features of an autoimmune disease. Inflammation is rampant, and autoantigens are identifiable with purified auto-antibodies. The principal auto-antigen appears to be a microfibrillar protein with similarities to fibrinogen localizing to adventitia of the aorta. It has seven loci for potential tyrosine nitration. NO in tobacco smoke may nitrate this protein, which would be expected to enhance its immunogenicity. Anti-fibrinogen antibodies promote AAA in mouse models. Finally, antibodies against fibrinogen are detectable in humans with AAA. These findings suggest that smoking heightens autoimmunity in AAA in humans and mice. The autoimmune hypothesis does not exclude other possible explanations for the smoking/AAA association. 


\section{Conflict of Interest}

\section{Comment on this Article or Ask a Question}

The author has no conflict of interest relevant to this publication.

\section{References}

1. Gretarsdottir S, Baas AF, Thorleifsson G, Holm $\mathrm{H}$, den Heijer M, de Vries JP, et al. Genome-wide association study identifies a sequence variant within the DAB2IP gene conferring susceptibility to abdominal aortic aneurysm. Nat Genet. 2010;42:692-697. DOI: $10.1038 / \mathrm{ng} .622$

2. Helgadottir A, Thorleifsson G, Magnusson KP, Gretarsdottir S, Steinthorsdottir V, Manolescu $A$, et al. The same sequence variant on 9p21 associates with myocardial infarction, abdominal aortic aneurysm and intracranial aneurysm. Nat Genet. 2008;40:217224. DOI: $10.1038 / \mathrm{ng} .72$

3. Norman PE, Curci JA. Understanding the effects of tobacco smoke on the pathogenesis of aortic aneurysm. Arterioscler Thromb Vasc Biol. 2013;33:1473-1477. DOI: 10.1016/j.jvs.2007.01.058

4. Bergoeing MP, Arif $B$, Hackmann $A E$, Ennis TL, Thompson RW, Curci JA. Cigarette smoking increases aortic dilatation without affecting matrix metalloproteinase- 9 and -12 expression in a modified mouse model of aneurysm formation. J Vasc Surg. 2007;45:1217-1227. https://doi.org/ 10.1016/j.jvs.2007.01.058

5. Stolle K, Berges A, Lietz M, Lebrun S, Wallerath $\mathrm{T}$. Cigarette smoke enhances abdominal aortic aneurysm formation in angiotensin II-treated apolipoprotein E-deficient mice. Toxicol Lett. 2010;199:403-409. DOI: 10.1016/j.toxlet.2010.10.005

6. Tilson MD. Decline of the atherogenic theory of the etiology of the abdominal aortic aneurysm and rise of the autoimmune hypothesis. J Vasc Surg. 2016;64:1523-1525. DOI: 10.1016/j.jvs.2016.06.119

7. Jagadesham VP, Scott DJ, Carding SR. Abdominal aortic aneurysms: an autoimmune disease? Trends Mol Med. 2008;14:522529. DOI: 10.1016/j.molmed.2008.09.008

8. Chang TW, Gracon AS, Murphy MP, Wilkes DS. Exploring autoimmunity in the pathogenesis of abdominal aortic aneurysms. Am J Physiol Heart Circ Physiol. 2015;309:H719-H727. DOI: 10.1152/ ajpheart.00273.2015

9. Clifton MA. Familial abdominal aortic aneurysms. Br J Surg. 1977;64:765-766. DOI: 10.1002/bjs.1800641102

10. Tilson MD, Stansel HC. Differences in results for aneurysm vs occlusive disease after bifurcation grafts: results of
100 elective grafts. Arch Surg. 1980;115: 1173-1175. PMID: 7425827

11. Tilson MD, Seashore MR. Human genetics of the abdominal aortic aneurysm. Surg Gynecol Obstet. 1984;158:129-132. PMID: 6695305

12. Tilson MD, Seashore MR. Fifty families with abdominal aortic aneurysms in two or more first-order relatives. Am J Surg. 1984;147:551-553. DOI: 10.1016/00029610(84)90020-5

13. Johansen K, Koepsell T. Familial tendency for abdominal aortic aneurysms. JAMA. 1986;256:1934-1936. DOI: https://doi.org/ 10.1001/jama.1986.03380140104031

14. Tilson MD, 3rd, Ro CY. The candidate gene approach to susceptibility for abdominal aortic aneurysm: TIMP1, HLA-DR-15, ferritin light chain, and collagen XI-Alpha-1. Ann N Y Acad Sci. 2006;1085:282-290. DOI: 10.1196/annals.1383.016

15. Tilson MD, Reilly JM, Brophy CM, Webster EL, Barnett TR. Expression and sequence of the gene for tissue inhibitor of metalloproteinases in patients with abdominal aortic aneurysms. J Vasc Surg. 1993;18:266-270. DOI: 10.1016/0741-5241(93)90607-N

16. Hinterseher I, Krex D, Kuhlisch E, Schmidt KG, Pilarsky C, Schneiders W, et al. Tissue inhibitor of metalloproteinase-1 (TIMP-1) polymorphisms in a Caucasian population with abdominal aortic aneurysm. World J Surg. 2007;31:2248-2254. DOI: 10.1007/ s00268-007-9209-x

17. Tilson MD, Ozsvath KJ, Hirose $H$, Xia S. A genetic basis for autoimmune manifestations in the abdominal aortic aneurysm resides in the MHC class II locus DR-beta-1. Ann N Y Acad Sci. 1996;800:208-215. PMID: 8958995

18. Hirose $\mathrm{H}$, Takagi M, Miyagawa N, Hashiyada $H$, Noguchi M, Tada S, et al. Genetic risk factor for abdominal aortic aneurysm: HLA-DR2(15), a Japanese study. J Vas Surg. 1998;27:500-503. DOI: 10.1016/S07415214(98)70324-6

19. Tromp G, Ogata T, Gregoire L, Goddard KA, Skunca M, Lancaster WD, et al. HLADQA is associated with abdominal aortic aneurysms in the Belgian population. Ann N Y Acad Sci. 2006;1085:392-395. DOI: 10.1196/annals.1383.045

20. Sandford RM, Bown MJ, London NJ, Sayers $\mathrm{RD}$. The genetic basis of abdominal aortic aneurysms: a review. Eur J Vasc Endovasc Surg. 2007;33:381-390. DOI: 10.1016/j. ejvs.2006.10.025

21. Jones GT, Tromp G, Kuivaniemi $H$, Gretarsdottir S, Baas AF, Giusti B, et al. Meta-analysis of genome-wide association studies for abdominal aortic aneurysm identifies four new disease-specific risk loci. Circ Res. 2017;120:341-353. DOI: 10.1161/CIRCRESAHA. 116.308765

22. Saratzis A, Bown MJ, Wild B, Nightingale $P$, Smith J, Johnson C, et al. Association between seven single nucleotide polymorphisms involved in inflammation and proteolysis and abdominal aortic aneurysm. J Vasc Surg. 2015;61:1120-1128.e1. DOI: 10.1016/j.jvs.2013.11.099

23. Do C, Shearer A, Suzuki M, Terry MB, Gelernter J, Greally JM, et al. Geneticepigenetic interactions in cis: a major focus in the post-GWAS era. Genome Biol. 2017;18:120. DOI: 10.1186/s13059017-1250-y

24. Breitling LP. Current genetics and epigenetics of smoking/tobacco-related cardiovascular disease. Arterioscler Thromb Vasc Biol. 2013;33:1468-1472. DOI: 10.1161/ATVBAHA.112.300157

25. Joehanes R, Just AC, Marioni RE, Pilling LC, Reynolds LM, Mandaviya PR, et al. Epigenetic signatures of cigarette smoking. Circ Cardiovasc Genet. 2016;9:436-447. DOI: 10.1161/CIRCGENETICS.116.001506

26. Beckman EN. Plasma cell infiltrates in atherosclerotic abdominal aortic aneurysms. Am J Clin Pathol. 1986;85:21-24. PMID: 3940417

27. Johnston KW, Rutherford RB, Tilson MD, Shah DM, Hollier L, Stanley JC. Suggested standards for reporting on arterial aneurysms. Subcommittee on Reporting Standards for Arterial Aneurysms, Ad Hoc Committee on Reporting Standards, Society for Vascular Surgery and North American Chapter, International Society for Cardiovascular Surgery. J Vasc Surg. 1991;13:452-458. DOI: 10.1067/ mva.1991.26737

28. Brophy CM, SGS, Tilson MD. Pathology of nonspecific abdominal aneurysm disease. In: Greenhalgh RMJ, editor. Current Therapies in Vascular Surgery II. London: B.C. Decker, Inc; 1990. pp. 221-226.

29. Brophy CM, Reilly JM, Smith GJ, Tilson MD. 
The role of inflammation in nonspecific abdominal aortic aneurysm disease. Ann Vasc Surg. 1991;5:229-233. DOI: 10.1007/ BF02329378

30. Koch AE, Haines GK, Rizzo RJ, Radosevich JA, Pope RM, Robinson PG, et al. Human abdominal aortic aneurysms. Immunophenotypic analysis suggesting an immune-mediated response. Am J Pathol. 1990;137:1199-1213. PMID: 1700620

31. Tilson MD. Aortic aneurysms and atherosclerosis. Circulation. 1992;85:378-379. PMID: 1728475

32. Sumpio B, Tilson MD. Do aneurysms cause atherosclerosis? Ann N Y Acad Sci. 1996;800:268-269. DOI: 10.1111/j.17496632.1996.tb33328.x

33. Saraff K, Babamusta F, Cassis LA, Daugherty $A$. Aortic dissection precedes formation of aneurysms and atherosclerosis in angiotensin II-infused, apolipoprotein E-deficient mice. Arterioscler Thromb Vasc Biol. 2003;23:1621-1626. DOI: 10.1161/01. ATV.0000085631.76095.64

34. Johnsen SH, Forsdahl SH, Singh K, Jacobsen BK. Atherosclerosis in abdominal aortic aneurysms: a causal event or a process running in parallel? The Tromso study. Arterioscler Thromb Vasc Biol. 2010;30:1263-1268. DOI: 10.1161/ATVBAHA. 110.203588

35. Platsoucas CD, Lu S, Nwaneshiudu I, Solomides C, Agelan A, Ntaoula N, et al. Abdominal aortic aneurysm is a specific antigen-driven T cell disease. Ann N Y Acad Sci. 2006;1085:224-235. DOI: 10.1196/annals.1383.019

36. Lu S, White JV, Lin WL, Zhang X, Solomides C, Evans K, et al. Aneurysmal lesions of patients with abdominal aortic aneurysm contain clonally expanded T cells. J Immunol. 2014;192:4897-4912. DOI: 10.4049/ jimmunol.1301009

37. Reilly JM, Brophy CM, Tilson MD. Characterization of an elastase from aneurysmal aorta which degrades intact aortic elastin. Ann Vasc Surg. 1992;6:499-502. DOI: 10.1007/BF02000820

38. Newman KM, Malon AM, Shin RD, Scholes JV, Ramey WG, Tilson MD. Matrix metalloproteinases in abdominal aortic aneurysm: characterization, purification, and their possible sources. Connect Tissue Res. 1994;30:265-276. PMID: 7956205

39. Irizarry $E$, Newman KM, Gandhi RH, Nackman GB, Halpern V, Wishner S, et al. Demonstration of interstitial collagenase in abdominal aortic aneurysm disease. J Surg Res. 1993;54:571-574. DOI: 10.1006/ jsre.1993.1087

40. Newman $\mathrm{KM}$, Ogata $\mathrm{Y}$, Malon AM, Irizarry $\mathrm{E}$, Gandhi RH, Nagase H, et al. Identification of matrix metalloproteinases 3 (stromelysin-1) and 9 (gelatinase B) in abdominal aortic aneurysm. Arterioscler Thromb. 1994;14:1315-13120. PMID: 8049193

41. Newman KM, Jean-Claude J, Li H, Scholes JV, Ogata Y, Nagase $\mathrm{H}$, et al. Cellular localization of matrix metalloproteinases in the abdominal aortic aneurysm wall. J Vasc Surg. 1994;20:814-820. DOI: 10.1016/ S0741-5214(94)70169-5

42. Newman KM, Jean-Claude J, Li H, Ramey WG, Tilson MD. Cytokines that activate proteolysis are increased in abdominal aortic aneurysms. Circulation. 1994;90:li224-li227. PMID: 7955258

43. Pyo R, Lee JK, Shipley JM, Curci JA, Mao D, Ziporin SJ, et al. Targeted gene disruption of matrix metalloproteinase-9 (gelatinase B) suppresses development of experimental abdominal aortic aneurysms. J Clin Invest. 2000;105:1641-1649. DOI: $10.1172 / \mathrm{JCl} 8931$

44. Longo GM, Xiong W, Greiner TC, Zhao $Y$, Fiotti N, Baxter BT. Matrix metalloproteinases 2 and 9 work in concert to produce aortic aneurysms. J Clin Invest. 2002;110:625-632. DOI: 10.1172/JCI15334

45. Li ZZ, Guo ZZ, Zhang Z, Cao QA, Zhu YJ, Yao $\mathrm{HL}$, et al. Nicotine-induced upregulation of VCAM-1, MMP-2, and MMP-9 through the alpha7-nAChR-JNK pathway in RAW264.7 and MOVAS cells. Mol Cell Biochem. 2015;399:49-58. DOI: 10.1007/s11010-0142231-z

46. Wang $S$, Zhang $C$, Zhang $M$, Liang $B$, Zhu $H$, Lee $J$, et al. Activation of AMP-activated protein kinase alpha2 by nicotine instigates formation of abdominal aortic aneurysms in mice in vivo. Nat Med. 2012:18:902-910. DOI: 10.1038/nm.2711

47. Guo ZZ, Cao QA, Li ZZ, Liu LP, Zhang Z, Zhu YJ, et al. SP600125 Attenuates nicotine-related aortic aneurysm formation by inhibiting matrix metalloproteinase production and CC chemokine-mediated macrophage migration. Mediators Inflamm. 2016;2016:9142425. DOI: $10.1155 / 2016 / 9142425$

48. Maegdefessel L, Azuma J, Toh R, Deng A, Merk DR, Raiesdana A, et al. MicroRNA-21 blocks abdominal aortic aneurysm development and nicotine-augmented expansion. Sci Transl Med. 2012;4:122ra22. DOI: 10.1126/scitranslmed.3003441

49. Talukder MA, Johnson WM, Varadharaj S, Lian J, Kearns PN, El-Mahdy MA, et al. Chronic cigarette smoking causes hypertension, increased oxidative stress, impaired NO bioavailability, endothelial dysfunction, and cardiac remodeling in mice. Am J Physiol Heart Circ Physiol. 2011;300:H388-H396. DOI: 10.1152/ ajpheart.00868.2010

50. Capella JF, Paik DC, Yin NX, Gervasoni JE,
Tilson MD. Complement activation and subclassification of tissue immunoglobulin $\mathrm{G}$ in the abdominal aortic aneurysm. J Surg Res. 1996;65:31-33. DOI: 10.1006/ jsre.1996.0339

51. Gregory AK, Yin NX, Capella J, Xia S, Newman KM, Tilson MD. Features of autoimmunity in the abdominal aortic aneurysm. Arch Surg. 1996;131:85-88. PMID: 8546584

52. Chew DK, Knoetgen J, Xia S, Tilson MD. The role of a putative microfibrillar protein $(80 \mathrm{kDa})$ in abdominal aortic aneurysm disease. J Surg Res. 2003;114:25-29. DOI: 10.1016/S0022-4804(03)00208-7

53. Xia S, Ozsvath K, Hirose $\mathrm{H}$, Tilson MD. Partial amino acid sequence of a novel 40-kDa human aortic protein, with vitronectin-like, fibrinogen-like, and calcium binding domains: aortic aneurysm-associated protein-40 (AAAP-40) [human MAGP-3, proposed]. Biochem Biophys Res Commun. 1996;219:36-39. DOI: 10.1006/ bbrc.1996.0177

54. Kobayashi $R$, Tashima $\mathrm{Y}$, Masuda $\mathrm{H}$, Shozawa T, Numata $Y$, Miyauchi $K$, et al. Isolation and characterization of a new $36-\mathrm{kDa}$ microfibril-associated glycoprotein from porcine aorta. J Biol Chem. 1989;264:17437-17444. PMID: 2793866

55. Ohmori H, Kanayama N. Immunogenicity of an inflammation-associated product, tyrosine nitrated self-proteins. Autoimmun Rev. 2005;4:224-229. DOI: 10.1016/j. autrev.2004.11.011

56. Ozsvath KJ, Hirose H, Xia S, Chew D, Knoetgen J 3rd, Tilson MD. Expression of two novel recombinant proteins from aortic adventitia (kappafibs) sharing amino acid sequences with cytomegalovirus. J Surg Res. 1997;69:277-282. DOI: 10.1006/ jsre. 1997.5030

57. Tilson MD, Rzhetsky A. A novel hypothesis regarding the evolutionary origins of the immunoglobulin fold. Curr Med Res Opin. 2000;16:88-93. PMID: 10893652

58. Chew DK, Knoetgen J 3rd, Xia S, Gaetz HP, Tilson MD. Regional distribution in human of a novel aortic collagen-associated microfibrillar protein. Exp Mol Pathol. 1999;66:59-65. DOI: 10.1006/exmp.1999.2238

59. Hirose H, Ozsvath KJ, Xia S, Gaetz HP, Tilson MD. Immunoreactivity of adventitial matrix fibrils of normal and aneurysmal abdominal aorta with antibodies against vitronectin and fibrinogen. Pathobiology. 1998;66:1-4. DOI: 10.1159/000027988

60. Borromeo JR, Koshy N, Park WM, Xia S, Hardy K, Tilson MD. Regional distribution in the mouse of proteins homologous to artery-specific antigenic proteins (ASAPs). J Surg Res. 1999;85:217-224. DOI: 10.1006/ jsre.1999.5659 
61. Norman PE, Powell JT. Site specificity of aneurysmal disease. Circulation. 2010;121:560-568. DOI: 10.1161/CIRCULATIONAHA.109.880724

62. Tyrie LS, FK, Luo J, Selegean S, Attiyeh M, Colln P, Konofagou E, et al. AneuMastat reduces aneurysm incidence in the angiotensin II (Ang-II)-induced model of AAA in the wildtype C57BL6 mouse. J Amer College Surg. 2007;205:S111. DOI: 10.1016/j. jamcollsurg.2007.06.277

63. Luo J, Fujikura K, Tyrie LS, Tilson MD, Konofagou EE. Pulse wave imaging of normal and aneurysmal abdominal aortas in vivo. IEEE Trans Med Imaging. 2009;28:477486. DOI: 10.1109/TMI.2008.928179

64. Jin J, Arif B, Garcia-Fernandez F, Ennis TL, Davis EC, Thompson RW, et al. Novel mechanism of aortic aneurysm development in mice associated with smoking and leukocytes. Arterioscler Thromb Vasc Biol. 2012;32:2901-2909. DOI: 10.1161/ATVBAHA.112.300208

65. Zhou HF, Yan H, Bertram P, Hu Y, Springer LE, Thompson RW, et al. Fibrinogen-specific antibody induces abdominal aortic aneurysm in mice through complement lectin pathway activation. Proc Natl Acad Sci U S A. 2013;110:E4335-E4344. DOI: 10.1073/pnas. 1315512110

66. Knoetgen J, Tilson MD. Detection of autoantibodies against an aortic antigenic protein as a screening test for AAA. Surgical Forum - Chicago. 1997;48:401-402.

67. Turko IV, Murad F. Protein nitration in cardiovascular diseases. Pharmacol Rev. 2002;54:619-634. PMID: 12429871

68. Radi R. Protein tyrosine nitration: biochemical mechanisms and structural basis of functional effects. Acc Chem Res. 2013;46:550559. DOI: $10.1021 / a r 300234 c$

69. Jin $\mathrm{H}$, Webb-Robertson BJ, Peterson ES, Tan R, Bigelow DJ, Scholand MB, et al. Smoking, COPD, and 3-nitrotyrosine levels of plasma proteins. Environ Health Perspect. 2011;119:1314-1320. DOI: 10.1289/ ehp. 1103745

70. Pignatelli B, Li CQ, Boffetta $P$, Chen $Q$, Ahrens W, Nyberg F, et al. Nitrated and oxidized plasma proteins in smokers and lung cancer patients. Cancer Res. 2001;61:778784. PMID: 11212282
71. Borland C, Higenbottam T. Nitric oxide yields of contemporary UK, US and French cigarettes. Int J Epidemiol. 1987;16:31-34. PMID: 3570619

72. Paik D, Tilson MD. Neovascularization in the abdominal aortic aneurysm. Endothelial nitric oxide synthase, nitric oxide, and elastolysis. Ann NY Acad Sci. 1996;800:277. DOI: 10.1111/j.1749-6632.1996.tb33331.x

73. Paik DC, Ramey WG, Dillon J, Tilson MD. The nitrite/elastin reaction: implications for in vivo degenerative effects. Connect Tissue Res. 1997;36:241-251. PMID: 9512892

74. Paik DC, Dillon J, Galicia E, Tilson MD. The nitrite/collagen reaction: non-enzymatic nitration as a model system for age-related damage. Connect Tissue Res. 2001;42:111-122. PMID 11718466

Cite this article as: Tilson MD. Autoimmunity in the Abdominal Aortic Aneurysm and its Association with Smoking. AORTA (Stamford). 2017;5(6):159-167. DOI: https://doi. org/10.12945/j.aorta.2017.17.693 